\title{
Wear characteristics of a W6Mo5Cr4V2 high speed steel in friction stir welding of AA6061/SiC/55p composite
}

\author{
Xuecheng Song ${ }^{1, a}$, Lijie Guo ${ }^{1, b}$, Xiaosong Feng ${ }^{1, c}$ and Fan Cui ${ }^{1, d}$ \\ ${ }^{1}$ Shanghai Aerospace Equipments Manufacturer, Shanghai, China 200245

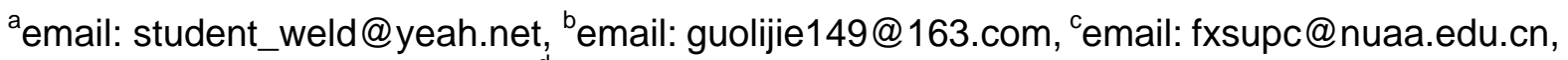 \\ demail: cuifan2004@126.com
}

Keywords: friction stir welding, aluminum matrix composite, high speed steel, wear characteristics

\begin{abstract}
Tool wear is a key issue for the friction stir welding (FSW) of aluminum matrix composites (AMCs), especially when the volume fraction of reinforcing particulates is relatively high. In this study, a tapered smooth tool of W6Mo5Cr4V2 high speed steel is used to weld a cast AMC composed of AA6061 matrix and 55 vol.\% SiC particulates so as to examine the wear characteristics of the tool. Experimental results indicate that the tool wear is appreciable although the shoulder height and pin length are changed slightly. The radial wear of the pin is also different at different locations of the pin.
\end{abstract}

\section{Introduction}

Particulates reinforced aluminum matrix composites (AMCs) are considered as one of the most promising structural materials for advanced applications in aerospace, military and transportation industries [1]. However, in order to produce larger or more complex structural components, it is inevitable to join AMCs to themselves or other materials. Therefore, some joining processes such as fusion welding[2][3], brazing [4] and diffusion bonding [5][6] were developed, but they resulted, to different extent, in the degradation of mechanical properties.

Friction stir welding (FSW) [7] is being considered as a prospective joining process to solve this problem. As a solid-state joining process, FSW can eliminate the welding defects associated with fusion welding processes. In the friction stir welded joints, there is no transition zone or bonding zone related to diffusion bonding or brazing. Therefore, the original properties of AMCs can be held. A few researchers carried out preliminary studies on this topic, and the feasibility of the FSW process was demonstrated[8][9]. However, the hard ceramic particulates in the AMCs resulted in appreciable tool wear when the FSW tool was made of tool steel[10]. In the present study, a W6Mo5Cr4V2 high speed steel was used to friction stir weld an AA6061/SiC/55p AMC, and the emphasis was placed on the wear characteristics of the tool.

\section{Experimental Procedure}

The base material, composed of AA6061 alloy matrix and 55 vol.\% SiC ceramic particulates, was a 2-mm thick cast AMC with the nominal compositions listed in Table 1. The FSW tool was made of a W6Mo5Cr4V2 high speed steel and the tool pin possessed a tapered smooth shape which was designed to reduce the tool wear. The tool shoulder was designated as a concave contour and the tool size is listed in Table 2. The AMC samples were butt welded by the counter-clockwise rotating tool under the process parameters of $800 \mathrm{rpm}$ rotational speed and $10 \mathrm{~mm} / \mathrm{min}$ welding speed. After any one couple of samples were welded, the tool was placed in a $5 \% \mathrm{NaOH}$ solution until the aluminum on the tool surface was completely removed, and then the tool was photographed using a digital camera. In this way, a series of tool photographs was obtained, and the variation in tool geometry was accurately calculated in a computer system. 
Table 1 Nominal compositions of AA6061/SiC/55p AMC

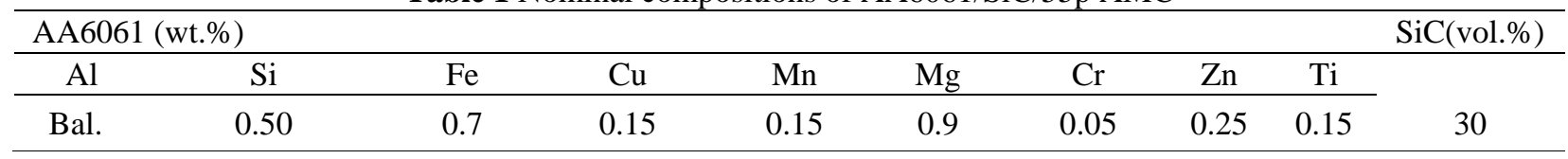

Table 2 Original size of the welding tool(mm)

\begin{tabular}{ccccc}
\hline Tool material & Shoulder diameter & Shoulder height & Pin diameter & Pin length \\
\hline W6Mo5Cr4V2 & 19 & 2 & 6 & 2 \\
\hline
\end{tabular}

Shoulder height was considered to be the same as the pin length.

\section{Results and Analysis}

Fig. 1 shows the appearance of the smooth tool after each FSW experiment. It can be seen from the figure that the pin profile changed a lot after welding of AMCs. The maximum wear occurs at the pin top while the minimum wear exists in the lower half-part near the shoulder. These results indicate that the tool is clearly consumed or its shape and size are significantly changed.

In order to quantitatively assess the tool wear, the percent variation in tool size is used as evaluation index, i.e. variation=(original size - measured size $) /($ original size $) \times 100 \%$.

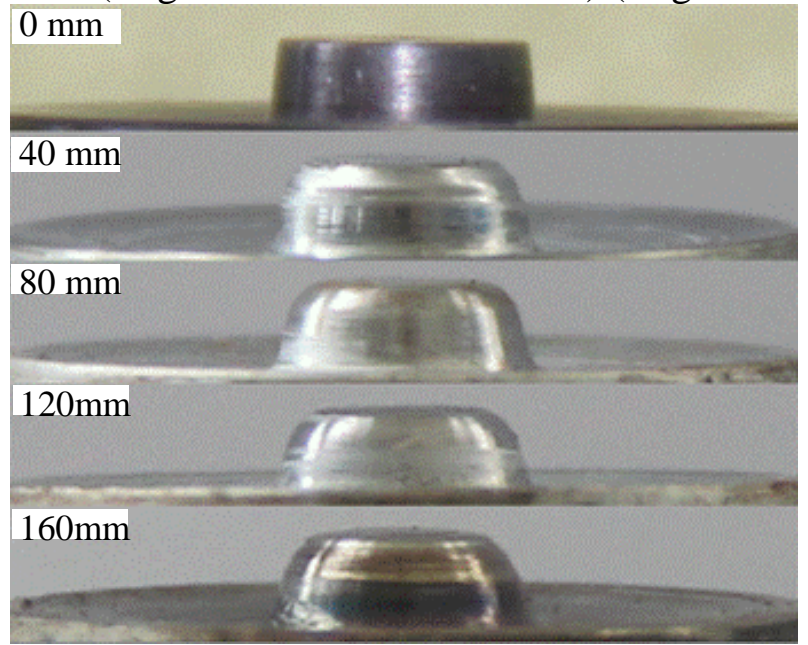

Fig.1 Appearance of the welding tool after different welding distances

As shown in Fig.2 and Fig.3, the variations in shoulder height and pin length increase with increasing travel distance, but they are all very small. For example, when the welding process is completed, the shoulder height and pin length are merely changed by 1.37 and 3.25\%, respectively. This implies that the shoulder wear and the pin longitudinal wear are slight.

Different from the variation in pin length, the variations in pin diameter are very remarkable, as shown in Fig.4. The pin diameter significantly decreases with increasing travel distance. For example, after an initial welding is performed at the welding speed of $10 \mathrm{~mm} / \mathrm{min}$, the pin diameter has at most decreased by $11 \%$. After the welding distance of $160 \mathrm{~mm}$ is performed, $21 \%$ of the pin diameter at the maximum wear location has disappeared. This indicates that the radial wear of the pin is appreciable.

It should be pointed out that the variations in pin diameter are not the same for different locations of the pin although they all increase with increasing travel distance. With respect to the two typical locations of 0.22 and $1.0 \mathrm{~mm}$ distant from the pin root, the low and high variations in pin diameter take place, respectively (see Fig. 5). This indicates that the radial wear of the pin is uneven at different locations of the pin. 


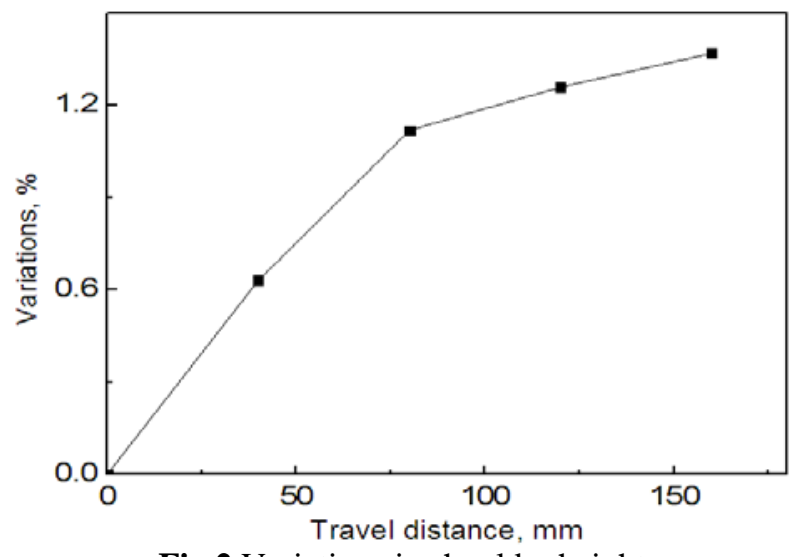

Fig.2 Variations in shoulder height

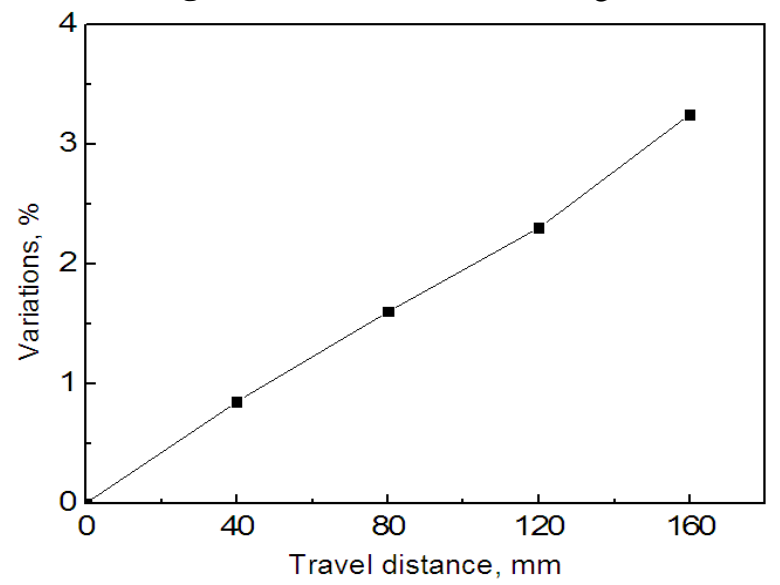

Fig.3 Variations in pin length

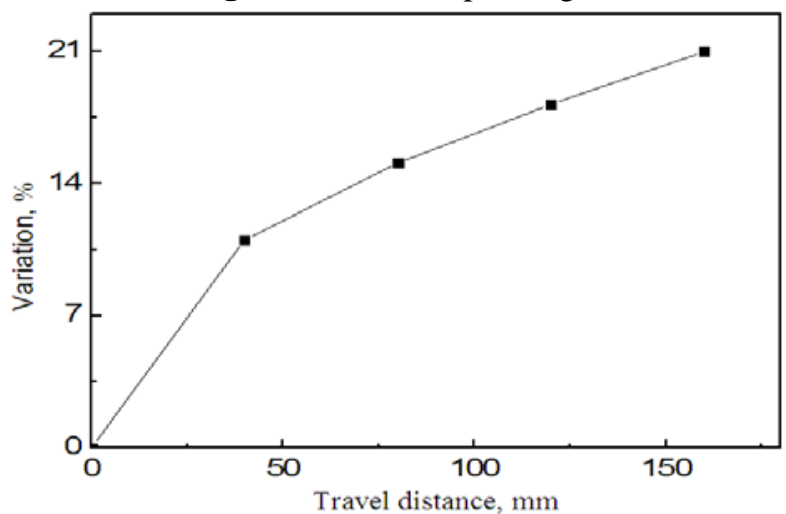

Fig.4 Variations in pin diameter at the pin top

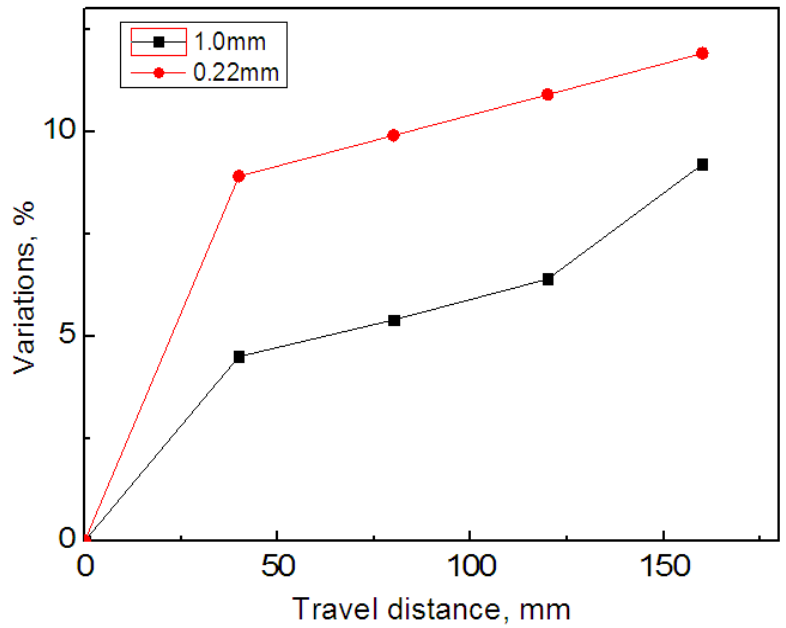

Fig.5 Variations in pin diameter at typical locations 


\section{Conclusion}

(1) An appreciable tool wear is observed in the FSW of AA6061/SiC/55p AMC with a tool material of W6Mo5Cr4V2 high speed steel.

(2) The shoulder height and pin length are changed slightly, and the radial wear of the pin top is most severe for the whole tool.

(3) The radial wear of the pin is different at different locations of the pin.

\section{Acknowledgement}

In this paper, the research was sponsored by the National Defense Basic Scientific Research (Project No. A0320110014) and Shanghai Excellent Technical Leader (Project No. 13XD1421300).

\section{References}

[1] J. Goni, P. Egizabal, J. Coleto, et al. High performance automotive and railway components made from novel competitive aluminum composites, Mater. Sci. Technol. 19 (2003) 930-934.

[2] A. Urena, M.D. Escalera, L. Gil. Influence of interface reactions on fracture mechanisms in TIG arc-welded aluminum matrix composites, Compos. Sci. Technol. 60 (2000) 613-622.

[3] H.M. Wang, Y.L. Chen, L.G. Yu. 'In-situ' weld-alloying/laser beam welding of SiCp/6061Al MMC, Mater. Sci. Eng. A 293 (2000) 1-6.

[4] X.P. Zhang, G.F. Quan, W. Wei. Preliminary investigation on joining performance of SiCp-reinforced aluminum metal matrix composite (Al/SiCp-MMC) by vacuum brazing, Composites Part A 30 (1999) 823-827.

[5] X.P. Zhang, L. Ye, Y.W. Mai, et al. Investigation on diffusion bonding characteristics of SiC particulate reinforced aluminum metal matrix composites (Al/SiCp-MMC), Composites Part A 30 (1999) 1415-1421.

[6 W.M. Thomas, E.D. Nicholas, J.C. Needham, et al. International patent application PCT/GB92/02203 and GB patent application 9125978.8, UK Patent Office, London, December 6, 1991.

[7] K. Nakata, S. Inoki, Y. Nakano, et al. Friction stir welding of Al2O3 particulate $6061 \mathrm{Al}$ alloy composite, Mater. Sci. Forum 426 (4) (2003) 2873-2878.

[8] T.W. Nelson, H. Zhang, T. Haynes. Friction Stir Welding of Aluminum MMC 6061-Boron Carbide, Proceedings of the Second International Symposium on Friction Stir Welding, Gothenburg, Sweden, 26-28 June, 2000 (Paper No. S08-P3).

[9] R.A. Prado, L.E. Murr, D.J. Shindo, et al. Tool wear in the friction-stir welding of aluminum alloy 6061C20\%Al2O3: a preliminary study, Scripta Mater. 45 (2001) 75-80.

[10] D.J. Shindo, A.R. Rivera, L.E. Murr. Shape optimization for tool wear in the friction-stir welding of cast Al359-20\%SiC MMC, J. Mater. Sci. 37 (2002) 4999-5005. 